\title{
"Circuloterapia”: uma metáfora para o enfrentamento da dor crônica em duas clínicas de dor
}

I ${ }^{1}$ Mônica Angelim Gomes de Lima, ${ }^{2}$ Leny Alves Bomfim Trad I

Resumo: Este artigo descreve e analisa a dinâmica da clínica de dor enquanto um "artefato complexo" do sistema terapêutico biomédico, explorando as múltiplas vozes e as relações dialógicas sobre dor e a interdisciplinaridade no cotidiano clínico de duas clínicas de dor situadas em hospitais-escola nas cidades de Salvador e São Paulo. Foi realizado estudo etnográfico orientado pela antropologia interpretativa, na qual se buscou a descrição de situações singulares e expressivas da dinâmica da clínica de dor (considerada enquanto um serviço, constituído no interior da Biomedicina, destinado ao cuidado da dor crônica). Tais situações expressam tensões e soluções construídas a partir do enfrentamento da dor crônica enquanto objeto complexo que impóe, a todos, flexibilidade. Essa experiência etnográfica focalizou quatro espaços terapêuticos: a sala de espera, o corredor, a consulta médica e as discussões de caso clínico. A descrição produzida ilumina as múltiplas vozes sobre dor e interdisciplinaridade no cotidiano da clínica. Os sentidos da circulação nos espaços terapêuticos, representado no texto a partir da metáfora "circuloterapia”, orientam essa discussão em torno dos limites e possibilidades da constituição e funcionamento deste serviço.
1 Doutora em Saúde Pública; professora adjunta do Departamento de Medicina Preventiva e SOCIAL da Faculdade de Medicina da Bahia/UFBA. Endereço eletrônico: angelim@ufba.br

2 Professora associada do Instituto de Saúde Coletiva da UFBA. Pós-doutora em Ciências Sociais. Endereço eletrônico: trad@ufba.br 
A dor crônica, seus enigmas e perplexidades para terapeutas e doentes e o lugar atual no interior da biomedicina para o seu tratamento - a clínica de dor oferecem um rico cenário para múltiplas aproximaçóes sobre cada um dos atores envolvidos, sobre o espaço físico e social em questão e sobre a dinâmica das relaçoos nele estabelecidas. Dentre os muitos aspectos a serem explorados a respeito deste espaço institucional, focalizamos neste trabalho o processo que envolve terapeutas e pacientes que se mobilizam em torno de uma diversidade de alternativas terapêuticas. Para iniciar esta discussão, é reproduzida, a seguir, uma anotação do diário de campo produzido na etnografia realizada no interior de duas clínicas de dor, a qual condensa inúmeras questôes que serão exploradas neste artigo:

Os residentes esperam por orientação da Dra. Maria (médica supervisora) para definir onde vão trabalhar hoje. Mais um pouco, chega Márcio, outro residente de anestesia em estágio no ambulatório de dor e desabafa:

- Acabei de ver um atendimento de uma paciente. Quando ela disse: "fui a Dr. fulano e quando ele me disse que eu não tinha nada, meu corpo todo adormeceu, todinho" aí eu concluí: "definitivamente eu estou num ambulatório de piti”. Demos risada, eu não esperava que ele dissesse isso tão espontaneamente. E ao tentar manter a conversa, comentei que, então, ele teria que aprender a tratar piti. Ele concordou em termos, quando Roberto o interpelou e propôs uma conclusão: "É porque esses pacientes têm que circular, o ambulatório de fibromialgia é assim, circula, manda para fisio, psico, depois volta". Pergunto se só isso melhora e ele respondeu seguro - melhora, é o que melhora. Continuamos a conversa e Márcio finaliza: "na verdade, estamos criando a circuloterapia de Dr. Roberto D., o paciente tem que circular, se não circular, não funciona”. Pergunto se basta mandar para os outros profissionais e Roberto afirma categoricamente: "Não, porque assim não circula e tem que circular". (Diário de Campo 30/05/2003, Clínica de Dor, São Paulo)

O médico residente, Márcio, expressou, com a espontaneidade que é peculiar a quem ainda não incorporou completamente um habitus (BOURDIEU, 1996), sua dificuldade em compreender o que aquela paciente trazia ao reagir à desqualificação de um médico sobre sua dor. Muito provavelmente, ele se identificou com este médico, pois se encontra, ainda, no início de um estágio em que uma das tarefas mais árduas é aprender a acreditar na dor do outro.

O depoimento atualiza algumas questôes postas pela dor crônica para médicos e doentes, algumas dessas exploradas por vários autores, inclusive por estas autoras em outros artigos (LIMA; TRAD 2007; 2008). Nesse sentido, alguns dos aspectos que se abrem nesta ilustração são: a invisibilidade da dor ao "olhar 
medico" (RHODES, 1999), colocando o doente sob suspeição, visto que sua

dor é desacreditada e descartada do escopo do cuidado médico; a inevitabilidade (KOTARBA, 1981) ou permanência da dor crônica como doença incurável, o que impõe o retorno do doente à procura da atenção médica, mesmo sabendo da possibilidade de rejeição; a incomunicabilidade (SCARRY, 1985) da dor e a tentativa de expressão por meio da metáfora do adormecimento do corpo como percepção incorporada do sofrimento.

Pretende-se discutir o que, exatamente, esses jovens médicos identificam e batizam de "circuloterapia". A descontração daquele momento permitiu que não ficassem apenas na constatação das dificuldades trazidas pela dor, mas que tentassem esboçar uma solução ou um caminho. Para Roberto, circular significa ser atendido pelos vários profissionais presentes na clínica de dor, alguns rapidamente nomeados por ele. Ele pode não saber por que estes doentes melhoram, mas tem certeza não só da melhora, como, sobretudo, da importância da circulação para esse resultado. Trata-se de uma terapêutica pautada na dinâmica do doente entre profissionais de saúde, mas que, nesse contexto específico, permite não só que o doente vá, mas que ele volte e, portanto, circule, para que o tratamento possa funcionar.

A ideia da "circuloterapia" poderia ser discutida sob vários aspectos: a garantia do retorno do paciente como estratégia mercadológica e forma de assegurar o cliente no consultório; como evidência de certo "descanso" do médico enquanto o paciente está circulando, já que implica distribuição da responsabilidade entre profissionais frente a um problema tão complexo, considerando-se o fato de que nenhum desses profissionais, isoladamente, tem condição, competência e habilidade suficientes para resolver o problema.

Se, por um lado, o reconhecimento da eficácia dessa circuloterapia mostra que a tecnologia médica sozinha não é suficiente para melhorar o sofrimento do doente, apontando, assim, para a perda da onipotência do médico, por outro revela o quanto ainda são desconhecidos para ele os mecanismos pelos quais essa circulação melhora a condição do doente e qual o papel dos demais profissionais de saúde na concretização do tratamento.

A etnografia realizada foi dirigida tanto para a escuta dos textos produzidos pelos terapeutas na prática clínica cotidiana sobre dor e sobre o sujeito que sofre de dor, quanto para o olhar sobre as dinâmicas presentes na circulação de doentes e terapeutas nesse espaço de tratamento dentro da escola médica. 


\section{Construindo a moldura teórico-metodológica}

Foi realizado um estudo etnográfico envolvendo duas clínicas de dor situadas em hospitais escolas de Salvador-BA e São Paulo-SP. Foram utilizadas técnicas pertinentes a esta abordagem, tais como entrevistas em profundidade (com 18 profissionais de saúde da clínica de Salvador e 13 da clínica de São Paulo) e observação participante (discussão de casos, triagem, conversas nos corredores etc.).

Em Salvador, o processo de observação participante transcorreu durante dois anos (julho/2002 a dezembro/2004), configurando, assim, o lócus privilegiado deste projeto. Já em São Paulo, foi possível a permanência por 40 dias (maio-junho/2003), durante os quais foi feito o acompanhamento das principais atividades do grupo, assim como foram realizadas entrevistas com os coordenadores dos serviços. As identidades dos entrevistados foram preservadas. Contou-se com o consentimento da direção técnica de ambas as instituições, assim como houve aprovação nos respectivos Comitês de Ética e assinatura dos termos de consentimento livre e esclarecido pelos participantes diretos.

A escolha desses locais foi respaldada pelas diferenças complementares existentes entre eles. O primeiro, a Clínica de Dor em Salvador, caracterizava-se, naquele momento, por ser um empreendimento relativamente recente (seis anos), embora vivendo crescimento rápido e afirmação institucional importante, seja pela ampliação da demanda, seja pela expansão da sua estrutura física e da equipe de profissionais. No caso da Clínica de Dor de São Paulo, esta foi incluída por se tratar do serviço mais antigo no Brasil (1979), sendo reconhecida, em nível nacional, pelo alto grau de amadurecimento institucional e técnico no campo do tratamento da dor crônica. Trata-se, assim, do principal centro de referência para o tratamento da dor no Brasil, além de ser responsável pela formação de grande parte dos especialistas da área e participar ativamente na produção de conhecimento deste campo em nível nacional e internacional.

Participaram deste estudo, em Salvador, 18 profissionais (8 médicos, 1 dentista, 4 psicólogos, 1 enfermeira, 1 fisioterapeuta e 3 instrutores de pilates) e seis pacientes; e da clínica de dor de São Paulo, 13 profissionais (8 médicos, 2 dentistas, 2 psicólogos e 1 enfermeira). Outros profissionais e pacientes, os quais não foram entrevistados, colaboraram durante a observação participante. Não houve recusas, apenas dificuldades operacionais que inviabilizaram algumas entrevistas. Definiu-se o critério da saturação pela repetição para estabelecer o momento do término das entrevistas. 
Recortando os espaços e

\section{descrevendo a dinâmica da circulação}

\section{Primeiro espaço de circulação: listas e salas de espera}

A clínica de dor tem várias salas de espera, mas, na terça-feira à tarde, a sala de espera é singular, revelando a intensidade do serviço. Desde o final da manhã começam a chegar os pacientes, embora a atendente repita que a antecipação é desnecessária, já que ela só começa a receber os cartões à uma hora da tarde. Ainda assim, a cena se repete a cada terça. Os doentes não só chegam cedo, como os mais antigos organizam sua própria fila, produzindo, inclusive, uma senha de papel bem recortada e plastificada. Alguns dizem que vêm de longe, até de outros municípios, e que têm que tentar antecipar ao máximo seu atendimento para conseguir retornar mais cedo. Nesta tarde são atendidos em torno de 80 doentes e, somados aos da acupuntura, que funciona no andar de cima, quase 130 doentes são atendidos, às terças, no ambulatório de dor.

São inúmeros cartões azuis e ouve-se a atendente perguntar repetidamente: é para psico, médico ou enfermeira? É aqui mesmo; para osteopatia e acupuntura? É lá em cima; quiropraxia? Não sei onde está, a última vez estava na sala da nutrição perto da [...]; Pilates? Marca aqui, mas atende fora? Onde fica? Onde está? Sendo assim, o início do atendimento é marcado pela localização e organização, iniciando-se o movimento de circulação desde o início. Faltam salas, mudam-se os locais de atendimento e a circulação tem um sentido explícito neste espaço.

O papel da atendente é fundamental. Apesar de passar despercebido no dia a dia, funciona como uma retaguarda que organiza o caos, o que é facilmente reconhecido quando a funcionária mais experiente e com maior afetividade com o serviço precisa se afastar por algum motivo. Nenhum outro atendente quer assumir este posto, sob a justificativa do excesso de trabalho (o que é visível, já no primeiro contato com o serviço) e da necessidade de um conjunto de informações que, se não disponibilizado, torna impossível o cumprimento da tarefa. Além disso, o papel da atendente requer habilidade para lidar tanto com os doentes, muitas vezes irritados, como com os médicos e demais profissionais do serviço.

São pilhas de prontuários que são deslocados do serviço de arquivamento (SAME) até os ambulatórios. Não raro faltam prontuários, especialmente quando um doente é atendido por mais de uma prática no mesmo dia ou no dia 
anterior - "hoje ela vai ser vista pelo médico, pela psico e pela fisioterapia". A atendente é responsável por iniciar o atendimento e orientar o fluxo que se segue.

$\mathrm{Na}$ sala de espera, uma televisão permanece ligada o tempo todo, mas nem por isso é observada. Enquanto esperam, os doentes conversam entre si. Existe, por um lado, a expectativa dos que esperam a triagem ou a primeira consulta, mas o que se observa, entre a maioria, é a troca de informações sobre os médicos e tratamentos. Na sala de espera da acupuntura, duas pacientes comentam sobre Dra. Laura, "ela usa acupuntura para tudo, lembra daquela menina com sinusite, com nariz entupido? Botava a agulha e desentupia tudo!" (DC 21/01/2003). Neste espaço, a troca de informações contribui para preparar as escolhas e conforma a participação dos doentes no seu itinerário terapêutico dentro da clínica de dor.

A dor, neste espaço, acentua o desconforto da espera, gerando irritabilidade e aumentando a expectativa frente ao tratamento. Por outro lado, motiva as trocas e o aprendizado entre os doentes sobre a sua dor e sobre as dinâmicas presentes na clínica de dor. O campo semântico da palavra "espera" agrega, ao ato de esperar, a esperança, assim como a demora, a dilatação, o adiamento (FERREIRA, 1988). Há uma espera ontológica para estes doentes. Na busca do cuidado, os doentes com dor ou com incapacidade aprendem a esperar, fato que se confirma pela presença de listas de espera no tratamento da dor em todo o mundo (BERKER et al., 1998; 2000).

\section{Espaço de circulação rápida, o corredor}

O corredor do ambulatório, na terça-feira, é o espaço onde são discutidos os casos clínicos. Algum tempo depois do início do atendimento, começam a surgir pequenos grupos formados por estudantes, médicos estagiários e preceptores. A forma de organização e o ritmo de apresentação da história e dos dados coletados variam conforme o responsável pela apresentação. A apresentação da história clínica, buscando trazer todos os detalhes e cumprindo rigorosamente o script da anamneses, é característica dos estudantes. Nesses casos, o preceptor geralmente permite que o ritmo seja seguido sem interrupções, até o momento em que requer uma síntese e orienta a observação:

Eva (Neurologista) discute com Paulo (graduando) sobre uma paciente, com dor cervical no braço e em face. É uma dor contínua, sem fatores de piora. Paulo apresenta uma anamnese longa e detalhada chama atenção ao roteiro didático colocando todas as informações positivas e negativas. Exame físico detalhado. Eva pergunta: "o que pediu? 
primeiro tem que localizar essa dor, você pode topografar essa dor? O que tem aí que

poderia doer? Músculo? Pulmão, não é. É preciso pensar uma só causa”. Eva lembra a história de câncer de mama (a paciente mencionou que uma irmã teve e retirou a mama). Paulo sugere que é psicológico. Eva concorda. Lúcia (enfermeira) pergunta "você descartou dor muscular?" Eva responde prontamente - "Não", sugere fazer uma eletroneuromiografia, mas comenta que é muito difícil conseguir... (DC 28/01/2003.)

A síntese da preceptora orienta a discussão em duas direções: a primeira para a espacialização da dor no corpo, segundo a qual topografar a dor é buscar as estruturas que doem nas diversas camadas desse corpo; a outra direção aponta para a etiologia psicológica da dor, associando a queixa da paciente à história familiar de câncer de mama. A dualidade corpo-mente e o "olhar medico" na busca da correlação entre dor e lesão estão presentes e orientam a decisão de solicitar o exame lembrado. Este exame poderá oferecer a visibilidade da dor ou reforçar a etiologia psicológica, o que poderá orientar a terapêutica a ser seguida.

Outra discussão presenciada exemplifica a ação dos médicos que faz os doentes circularem entre as práticas terapêuticas. A medicina física, entendida aqui como todas as práticas corporais, e a própria acupuntura são o eixo da terapêutica para alguns quadros, especialmente os que envolvem dor muscular (miofascial). A dificuldade que se apresenta em encaminhar os doentes revela a dificuldade de estabelecer mecanismos de circulação eficazes:

Mário discute com Eva uma paciente com cervicalgia, lista as medicações que está
usando, é hipertensa também. Retirou o relaxante muscular porque a paciente não fez
uso e comenta "tratar esse tipo de dor sem terapia física é 'lasca' [difícil], a gente está
sem o controle daquela lista". Refere-se à lista para agendamento do pilates, osteopa-
tia, acupuntura (DC 21/01/2003).

Os momentos da prescrição e da efetivação da terapêutica novamente são delimitados pela lista de espera. Não ter o controle sobre "aquela lista" significa que o médico não sabe como está o fluxo de atendimento dessas outras terapêuticas, pois, inclusive, algumas não acontecem no mesmo espaço físico nem no mesmo dia. Disponibilizar essas terapêuticas imediatamente após a consulta médica é muito difícil. A velocidade de encaminhamento dos doentes pelos médicos e a capacidade de absorvê-los pelas diversas práticas são muito diferentes, visto que cada médico atende, em média, oito doentes por dia e cada prática corporal ou psicológica propõe, inicialmente, realizar 10 ou 12 sessões para cada doente.

São diferentes modos operatórios (BASZANGER, 1989) e ritmos de trabalho. $\mathrm{O}$ médico vê o doente a cada três ou quatro meses, ou mais, e as práticas corporais 
e a acupuntura, por sua vez, requerem tempo e repetição, ainda mais porque, frequentemente, as 10 sessões padronizadas não são suficientes. Algumas vezes, no próximo retorno ao médico, o doente ainda não conseguiu cumprir outra fase do tratamento que não a própria medicação (mesmo esta, com muitas dificuldades).

$\mathrm{O}$ corredor também se configura enquanto espaço no qual se tentam superar essas dificuldades. Os terapeutas, médicos e estudantes, conversam, discutem rapidamente os casos, trocam ideias e agem no sentido de agilizar a sequência do tratamento, mobilizando-se frente à necessidade urgente de um determinado tipo de atendimento. Ir pessoalmente à sala da acupuntura tentar uma vaga, conversar com as psicólogas sobre a necessidade de algum doente, falar com a osteopata ou mesmo ligar para o pessoal do pilates (como é conhecido o grupo) são movimentações corriqueiras.

A dinâmica observada é viabilizada pela presença de todos na terça-feira, seja em atendimento, seja nas discussões no final do dia. É importante notar o fato de que esse movimento ocorre numa via de mão-dupla, pois os demais terapeutas, especialmente os da psicologia, também se mobilizam em direção aos médicos, seja para questionar o uso de determinadas medicações, seja para relatar a apreensão dos pacientes com relação a determinados procedimentos.

No corredor, a dor precisa de um diagnóstico e da decisão sobre o sentido da circulação do paciente no serviço. Trata-se, assim, do local que permite viabilizar a circulação do doente. A ponderação quanto às dimensões mais atingidas pela dor (o corpo ou a mente) orienta a tomada de decisão sobre os recursos terapêuticos e a avaliação quanto à priorização de um doente com relação a outros. A suspeita de doença psiquiátrica como a depressão, por exemplo, mobiliza os terapeutas médicos e psicólogos no sentido de agilizar o atendimento necessário.

\section{Espaço de circulação de discursos,}

\section{jeitos e gestos: os assentos e a autoridade da fala}

As discussões de casos clínicos e discussões temáticas, realizadas na terça-feira à noite, constituem, em vários sentidos, um espaço peculiar no interior da clínica. Em um mesmo momento, é possível reunir praticamente todos os membros responsáveis pelo cuidado no grupo de dor e, desde o primeiro dia, a pluralidade chama a atenção: as roupas, os jeitos e os gestos. 
A maioria se veste com um jaleco branco com seu nome bordado no bolso, reproduzindo, assim, um hábito comum no meio médico. Com o tempo, observa-se que se tratam não só de médicos, mas de estudantes de medicina, enfermeiras e psicólogas. A diversidade realmente se observa com a chegada "das meninas do pilates”, vestidas com roupas de ginástica, e que sempre chamam a atenção de todos e da pesquisadora, especialmente, ao ver dentro do hospitalescola personagens tão diferentes desse ambiente participando da discussão de casos clínicos.

A massoterapeuta, a osteopata e, sobretudo, as psicanalistas, reforçam esta heterogeneidade que se confirma, posteriormente, nas falas e nos diferentes olhares sobre o doente e a doença. A distribuição dos terapeutas na sala também sugere uma dinâmica, ainda mais pelo fato de que se trata de uma sala em forma de auditório, no qual as filas se dispõem de forma ascendente, organizadas em degraus. Posicionamo-nos, via de regra, na última fila, para obter uma melhor visualização do grupo.

Nas primeiras filas estão os de branco. Da terceira fila em diante acomodamse o grupo de pilates, três ou quatro dançarinas, a massoterapeuta e a osteopata. O musicoterapeuta fica geralmente num canto, do lado direito ou esquerdo e fala pouco (também quase não o vemos no ambulatório). Ele se afasta do grupo logo após nossa chegada.

A acupuntura, representada pela médica coordenadora e alguns estagiários, não se distingue da maioria, pois o grupo também é formado por médicos. Sua presença só se evidencia quando duas ou três pessoas são agulhadas em plena reunião: dores, cansaço e desânimo desencadeiam pequenos atendimentos e pequenos alívios.

De modo geral, a reunião de toda a equipe, nas terças à noite, é o espaço para discussão de dois tipos de caso: o difícil, aquele que ninguém ainda conseguiu resolver, e também o que deu certo, no qual o doente que apresenta melhora devido à conduta assumida. Os casos são apresentados através de um esquema ordenado de apresentação médica: a queixa, a história clínica, o exame físico, exames complementares e o diagnóstico. Em um segundo momento, é apresentado o que foi feito por cada terapeuta e a evolução do doente é descrita. A seguir, apresentamos um exemplo de cada tipo de caso e seus desdobramentos. 
10 Caso: diante da recusa aos recursos terapêuticos, o que fazer? Trata-se de uma paciente que vem passando por vários profissionais e mostra-se não cooperativa com o tratamento.

Paula (psicóloga) - apresenta o caso de Dolores seguindo o protocolo de avaliação psicológica. Conclui que a maior conquista da paciente foi o casamento e a maior perda foi a separação dos pais. Fala do trabalho como prazeroso. Sobre a família cita as palavras da paciente: "eles estão sem paciência comigo". Acha que a paciente está em franca depressão, mas recusa o tratamento. Arthur comenta: "quem mais precisa é quem mais se recusa". Pergunto: Quem é o médico que a atende? Arthur informa que todos os médicos a atendem. A paciente se recusa a ir para o psiquiatra e usar antidepressivo. Diz que não tem o que aprender com isso, "o problema da dor é só meu”. Está no ambulatório há quase dois anos. Paula relata uma fala da paciente "Eu só vim aqui para te dizer que eu não vou fazer, não preciso de psicólogo". Trata o atendimento psicológico com desprezo, mas liga para o celular de Paula. Refere que dói o estômago. "O remédio cai no estômago e parece uma bomba atômica, sinto a ferida se formar" A paciente acredita que todos os remédios são venenos. Está certa que vai ter um câncer. Tudo o que não é remédio traz um benefício enorme, embora temporário. A paciente considera que a osteopatia dá um alívio extraordinário, mas "a raiva é que é só hoje, amanhã volta, sempre volta”. Acredita que a dor está relacionada à sobrecarga de trabalho e a não saber dizer não.

$[\ldots]$

Paula mostra algumas etapas da avaliação psicológica: nos desenhos da figura humana a menina está triste o menino está feliz - diz que é o filho. Ao aplicar as escalas de ansiedade e depressão, confirma o diagnóstico. - eu devolvo para a paciente, mas nada dá certo. A paciente, após a devolução da avaliação psicológica, não aceita o encaminhamento para o psiquiatra porque "vai passar mais um remédio que não vou tomar". Paula chama atenção da importância do diagnóstico de depressão e o quanto a dor crônica é misturada com depressão. Arthur interpela "Esta paciente tem um gozo dessa doença, ela não colabora. No Rio Grande do Sul já teria sido desligada”. A psicanalista diz que este caso é super difícil eticamente. Existe um diagnóstico e há uma necessidade de tratamento. Fala da necessidade de essa paciente ser vista por um psiquiatra. Paula relata a dificuldade do atendimento psiquiátrico, dentro e fora do hospital-escola. Outra psicanalista, Valéria, pergunta: Você vai tratar? Paula responde: "Não, ela vai ser encaminhada” e propõe-se a estudar mais depressão no próximo semestre. (DC 22/05/2002)

Trata-se de uma discussão difícil para todos os terapeutas. A paciente se rebela à proposta terapêutica, ignora os diagnósticos e recusa as indicaçôes, embora se apresente regularmente ao serviço e aceite bem todas as terapêuticas não medicamentosas a ela oferecidas. Ao mesmo tempo, possui um diagnóstico que não pode ser ignorado e que precisa de tratamento. Para os médicos e psicólogos, o tratamento medicamentoso é fundamental, e o comportamento de recusa do tratamento também pode estar sendo influenciado pelo próprio quadro de depressão 
da paciente. Nem sempre uma solução é alcançada ao final de uma discussão como essa, no entanto, vários aspectos que emergem nesse momento merecem atenção.

O caso é apresentado e discutido, sobretudo pelo grupo de profissionais da psicologia e psicanálise, que são, no caso, as vozes autorizadas. Por outro lado, quando se configura uma doença, a depressão, o médico, nesse caso o psiquiatra, passa a ocupar o papel central na intervenção. $\mathrm{O}$ coordenador do grupo tenta interferir, nesse momento, citando outra clínica de dor que não admitiria essa doente, mas a psicanalista responde e chama pela responsabilidade ética com a paciente, o que é aceito pelo grupo, determinando a necessidade de continuidade do trabalho da psicologia como alternativa adequada ao tratamento. Nesse caso, a dor adquire o sentido do sofrimento psíquico ou da doença mental. Após a avaliação do médico, da psicóloga e da fisioterapeuta, observa-se que todos ficam como que paralisados diante de Dolores, de sua dor e sua rebeldia. No caso dela, a equipe concorda que a dor está ao lado da depressão, ou é a mesma coisa, ninguém sabe direito.

O fato posto para esses terapeutas é que, diante de um diagnóstico, é preciso agir. Nesse caso, ainda que a recusa do doente os imobilize, a decisão por manter os atendimentos que aliviam a dor é uma decisão básica e fundamental para que se continue uma estratégia de persuasão que tem, como objetivo principal, a continuidade do tratamento na aceitação, pela paciente, da abordagem psiquiátrica. Sendo assim, a palavra final, e portanto, mais autorizada, no tratamento de Dolores, é da psicologia e da psicanálise. Os demais profissionais deverão dar suporte a essa voz.

2 Caso: um caso com múltiplas abordagens e uma boa evolução. Para José Francisco, a dor na coluna lombar o tortura há muito tempo. Diferentemente de Dolores, José foi acompanhado pelo médico, psicóloga e pelo grupo de pilates. Tem uma melhora grande e já é possível pensar em alta. A dor permanece, mas os ganhos foram muito grandes. A alta não é fácil também para os terapeutas.

Arthur apresenta o caso clínico, descreve sintomatologia, exames, suspeita diagnóstica, tratamento e faz uma breve revisão da literatura, lembrando outras patologias.

Lara (psicóloga) - apresenta o mesmo caso. Começa também falando de sua experiência com esse paciente. "Ele não conseguia falar. Fiquei sobrecarregada, fiquei muito angustiada”. Relata sua experiência de aproximação com esse doente. Ele trocava pneus de caminhão sozinho. Ele dizia: "o trabalho prejudicou muito". 
Apresenta o esquema do atendimento: 18 sessões semanais, 6 quinzenais, 4 mensais. Descreve um pouco as sessões.

O paciente fala com a psicóloga sobre o medo de fazer bloqueio e de falar isso com Arthur.

Arthur - "a gente fazia bloqueios meio seriados, rapidamente, agora estamos fazendo o movimento contrário”

Lara - Comenta sobre a evolução do caso - "Acontece uma coisa, a gente trabalha, acha que regrediu. O paciente dá um passo para trás e dois para frente". Chama atenção para os avanços que o paciente teve. Mostra o teste da figura humana e comenta: "isto não é resultado da psicologia, mas do trabalho em equipe. Acho que temos conseguido alguma coisa” Acaba com palmas.

Laís (dançarina) - também o atendeu no pilates. Inicia sua descrição comentando sobre a gravidade do caso. Ela não conseguia nem avaliar o paciente, fazer o exame físico. Detalha seus objetivos e condutas no caso. Depois de 10-12 sessôes avaliou e observou melhora importante:

"Para mim foi também difícil deixar ele ir. Ele mudou muito a imagem corporal, tinha vontade de filmá-lo antes e depois"

"Ele às vezes falava coisas para mim que eu não sabia o que fazer - estou pensando em me matar - eu pensava - Meu Deus, o que eu faço com isso?” (DC 16/04/2002)

Este é um exemplo de quando o tratamento funciona bem em todas as suas etapas: o médico diagnosticou e medicou, a psicóloga avaliou e acompanhou, o grupo de pilates trabalhou com a reeducação postural e com o movimento e, como resultado, o doente melhorou e o sucesso terapêutico é remetido ao trabalho em equipe. Nesse caso, provavelmente porque foi alcançado sucesso no tratamento, o doente estabelece uma relação empática com os terapeutas e a alta ou o espaçamento dos atendimentos passa a ser discutida em conjunto.

A alta em uma clínica de dor não é um momento fácil nem para o doente, muito menos para o terapeuta. Por mais que haja uma ênfase no diagnóstico médico e na medicação, em todos os espaços de circulação o sofrimento mental costuma ser a segunda maior preocupação do grupo. Percebe-se que todos os profissionais demonstram uma atenção diferenciada para com essa temática, embora nem sempre saibam como agir a respeito.

\section{A circulação do doente e o doente que circula: espaços de negociação}

Nesse contexto, habitado por tantas vozes, e onde o principal objetivo é a modificação da experiência do doente sobre sua dor, por meio da oferta de 
múltiplas abordagens orientadas para o corpo, para a mente e para alguns espaços sociais (como a família e a seguradora de saúde), cabe reconhecer o lugar do doente enquanto objeto da intervenção terapêutica e como construtor de seu próprio itinerário terapêutico dentro da clínica de dor. Nesse sentido, observase, na figura do doente, um sujeito nem tão passivo, nem tão paciente, como habitualmente se observa nos doentes com dor aguda dentro da instituição médica. No caso da dor crônica, os doentes se posicionam, aprendem e se tornam aptos a identificar os tratamentos adequados ou não para a melhora de suas dores.

A doença crônica reposiciona o doente no centro do trabalho médico, como propõe Isabelle Baszanger (1989), ${ }^{1}$ pois parte da assunção de que sem a participação pela cooperação não é possível fazer nada pelo doente. Sendo assim, a técnica central que deve ser explorada pelo médico e pelos demais profissionais de saúde é a persuasão, para que este doente aceite entrar em um espaço onde cada um deles poderá trabalhar em diferentes perspectivas incluindo o corpo, o comportamento, a subjetividade.

Do ponto de vista do paciente, entrar neste espaço é mais do que se deslocar no espaço físico, significa estar aberto a experimentar em si os efeitos de múltiplas linguagens, aprendendo sobre si próprio através delas. Nesse processo necessário de persuasão, vários elementos poderão facilitar ou dificultar a adesão do doente ao tratamento: a expectativa do doente sobre a terapêutica, o grau de informação que ele possui sobre a abordagem ou sobre um terapeuta em particular, a empatia estabelecida com o terapeuta e a possibilidade de manutenção da terapêutica fora do espaço da clínica.

$\mathrm{Na}$ clínica de dor, a movimentação dos doentes entre as terapêuticas não é uma decisão puramente médica, apesar de a figura médica ser a responsável por definir o próximo passo no tratamento e por monitorar o conjunto dos recursos terapêuticos utilizados por cada doente. A circulação entre as diversas práticas parece constituir um grande atrativo entre os doentes, como demonstra esse breve diálogo entre duas pacientes na sala de espera: "Já fiz tudo aqui, acupuntura, osteopatia, hipnose, musicoterapia, psicologia... O que mais gostei foi o pilates [...] tenho que conseguir voltar" (DC 18/03/2003). No dia da avaliação médica dessa paciente, provavelmente, este tema retornará.

Percebe-se, no mesmo sentido, que a própria limitação de cada terapêutica a 10 ou 12 sessões não constitui um posicionamento rigoroso, especialmente nos casos 
em que o doente já passou por várias práticas e consegue reconhecer sua melhora a partir, especificamente, de uma delas. Sendo assim, esse aprendizado do doente sobre as respostas de sua dor às diferentes terapêuticas facilita o trabalho médico. Por outro lado, a viabilidade em manter um atendimento sem limite de tempo dentro da clínica de dor representa um dos principais desafios enfrentados pelo serviço, tendo em vista a cronicidade dos casos e a pressão que se estabelece pela constante demanda de novos doentes.

Observa-se que as terapêuticas não-convencionais têm um atrativo especial, à medida que são reconhecidas pela maioria dos doentes como uma importante fonte de alívio. No caso específico da acupuntura, alguns têm dificuldade com as agulhas, sentindo-se, assim, mais atraídos pelas práticas manuais e atividades físicas. Por conta disso, o serviço de acupuntura tem capacidade de receber um grupo maior de doentes toda tarde. Os procedimentos costumam ser rápidos e, após responder um roteiro sintético de perguntas padronizadas, o doente é “agulhado", devendo aguardar alguns minutos, deitado ou sentado, enquanto o médico atende outros doentes. No retorno do médico, quando o paciente é perguntado sobre o alívio, respondendo afirmativamente na maioria das vezes, as agulhas são retiradas e o doente é então liberado.

De maneira geral, o final da série de acupuntura é marcado pelo pedido de continuidade. Em um primeiro momento, os doentes tentam diretamente com o grupo da acupuntura, que algumas vezes cede e amplia o tratamento. Outras vezes, tentam com a pessoa responsável pela marcação, como fala Maria José (técnica de enfermagem): "as pacientes não querem deixar de fazer acupuntura, elas querem continuar fazendo sem limite" (DC 21/01/03, Zezé, técnica de enfermagem). Em uma tentativa de padronização da rotina do serviço, o grupo, em reunião administrativa, decidiu tornar mais rigoroso o acesso à reavaliação que se dá no retorno ao médico assistente.

A dificuldade em aceitar o uso contínuo das medicações é outro motivo que pode ser atribuído para a preferência pelas práticas não-convencionais. No trecho a seguir, duas terapeutas manuais (osteopata e massoterapeuta) conversam sobre os pacientes VIPs e a relação destas com as terapêuticas não-convencionais:

Clarice fala de Maria das Graças, paciente de 60 anos. "ela é VIP, acha ótimo os recursos alternativos a custo zero, ela tem resistência de usar medicação". Clarice fala de uma paciente que quer passar por todas as terapêuticas, diz "ela é fashion, quer tudo". Considera que é preciso um trabalho educativo paralelo às intervenções terapêuticas. (DC 20/08/2002) 
A opção pelas práticas não convencionais é mais explícita nos pacientes "VIPs", que costumam conhecer e estar informados sobre várias destas práticas. Geralmente, esses pacientes já chegam à clínica de dor com o objetivo claro de conseguirem acesso a estas. O mercado de saúde de práticas não convencionais encontra, no doloroso crônico, um cliente em potencial por longo tempo.

Da mesma forma que a medicação, que depois de ajustada deverá ser usada regularmente, essas outras abordagens também não têm previsão para terminar, a não ser pela própria evolução do doente e pelos recursos que ele desenvolve ao lidar com as variações da dor.

Percebeu-se, ainda, que as clínicas de dor estudadas têm também um caráter de centro de teste e divulgação dessas práticas. Dessa forma, ser voluntário na clínica de dor permite troca e reconhecimento mútuo entre profissionais, que passam a se referenciar uns aos outros fora do hospital-escola.

\section{As circulações e o fio do labirinto}

Ao longo desta descrição sobre a circulação de sentidos e de pessoas no espaço físico e social da clínica de dor, reconhecemos três tipos de circulação que chamam a atenção. A circulação diagnóstica, vivida pelos terapeutas e doentes na fase de avaliação e decisão da terapêutica, incluindo a admissão e a primeira avaliação de cada profissional; a circulação terapêutica, também experimentada e influenciada por ambos, mas que está voltada para a intervenção, mesmo que pontuada pela avaliação e pela lista de espera; a circulação iatrogênica, vivida pelo doente dentro e fora da clínica de dor, marcada pela repetição sem reflexão - neste caso, quer pela intervenção ou pela ausência desta, o doente simplesmente retorna, circula, mas não cresce.

Os dois primeiros tipos de circulação são complementares e interativos, numa perspectiva ideal, à medida que, em ambos, há o compromisso com a ação em direção ao cuidado (o que, por outro lado, não exclui a possibilidade de um mesmo doente vivenciar os três tipos de circulação).

Desde o momento em que é admitido, o doente inicia a circulação no interior da clínica. Embora, geralmente, já tenha experimentado vários outros recursos e lugares em seu itinerário terapêutico, dá início, nesse ponto, à interação com o espaço onde se condensam múltiplas linguagens e sentidos sobre a dor e sobre o cuidado. Estas diferentes linguagens e sentidos se encontram, por sua vez, impregnados em todos os espaços e sujeitos que aí se mobilizam. 
A circulação diagnóstica poderá ser mais ou menos prolongada conforme a agenda dos diversos serviços e a possibilidade de acesso aos exames complementares, o que, por vezes, pode se constituir enquanto um problema insolúvel. Já a circulação terapêutica permite reconhecer, nos diversos espaços de circulação rápida ou lenta, assim como na dramatização da apresentação dos casos clínicos, a multiplicidade de vozes engajadas num "diálogo posicionado", configurando o exercício da hetoroglossia (BRAIT, 1997; SILVA, 2003) enquanto uma forma de expressão da multiplicidade de vozes e da tensão inevitável entre sujeitos na afirmação de verdades, relações éticas e relações de consciência. Pode-se dizer que a ambiência característica produzida em um espaço terapêutico tal como a clínica de dor permite reconhecer essa dinâmica.

Como discutido em outro artigo (LIMA; TRAD, 2007), a dor crônica impõe a priorização do "projeto ético da terapêutica" em relação ao "projeto científico do estudo das doenças". Sayd (1998) explora a ideia da terapêutica como um recurso mais antigo, que situa o médico entre o doente e um saber, "medianeiro entre um e outro". Em sua discussão, o remédio é "a coisa concreta que melhor expressa (ou medeia) a aplicação do conhecimento a cada doente singular, a cada episódio de sofrimento" (SAYD, 1998, p. 175).

Ao longo deste estudo, temos sido instigadas a pensar que, no caso da dor crônica, a insuficiência da medicação acabou por exigir desses médicos ou desta medicina que lançassem mão de várias outras práticas não apenas como aplicaçōes de distintos remédios em distintos lugares ou dimensões (o corpo, a mente, a vida), mas pensadas como a inserção deste doente em uma dinâmica de busca e experiência de terapêuticas distintas que incluem a biomedicina. Nessa perspectiva, é possível compreender a circuloterapia como um "artefato terapêutico", que pressupõe acolher e inquietar, aliviar e permitir aberturas para outras experiências.

Artefato é aqui compreendido como o recurso utilizado para a intervenção do terapeuta sobre o doente. Nesse sentido, podem ser inúmeros os recursos, a depender da racionalidade médica. No caso específico da racionalidade biomédica, Madel Luz (1996) aponta o remédio como o principal artefato, como um elemento que permite, inclusive, a avaliação do desempenho médico pelos doentes. A autora amplia esta noção, argumentando que "seria, entretanto inexato, reduzir o 'arsenal terapêutico' da biomedicina ao medicamento. Atualmente os próprios exames funcionam, para os pacientes, como elemento terapêutico" (LUZ, 1996, p. 15). 
Continuando com esta linha de raciocínio, propomos que a clínica de dor inclui, nesse arsenal terapêutico, todas as práticas presentes em seu espaço, mas não como práticas isoladas, mas como parte desta dinâmica, a circuloterapia.

Se, por um lado, este "artefato terapêutico" resiste a ser submetido à rigidez dos protocolos dentro do hospital-escola; por outro, ele exige flexibilidade em vários sentidos, desde a organização do serviço, a escolha e a própria aplicação da terapêutica, como com relação ao que se pode esperar de seus resultados. Nesse sentido, a dor em si não poderá ser tomada como referência, já que ela se recusa a desaparecer, na maioria dos casos, exigindo que o olhar do terapeuta se dirija, então, ao cotidiano, à integração, à própria existência do doente. A impotência diante da dor requer a aproximação dos profissionais à experiência do doente, não pela via da objetivação da dor e do sofrimento, mas pela decodificação da "sua própria experiência a partir de necessidades e possibilidades trazidas pelo horizonte linguístico do outro" (AYRES, 2005, p. 557). Pode-se dizer, assim, que a dor crônica impõe a humanização do terapeuta.

\section{Considerações finais}

No enfrentamento da dor crônica, são reconhecidas possibilidades que emergem menos da rigidez da técnica e mais da vitalidade da prática de sujeitos, terapeutas e doentes, no exercício do cuidado da saúde. A insubordinação da dor à objetivação e a ampliação do leque de racionalidades e tradições para o seu cuidado criam condiçôes singulares (para o exercício do giro necessário do sucesso prático ("o que fazer") sobre o sucesso técnico ("como fazer") em direção a um projeto de felicidade humana (AYRES, 2001, p. 71).

A construção de um ponto de vista sensibilizado pela polifonia da dor crônica, disposto a explorar a possibilidade da multiplicidade de vozes presentes no drama do sofredor e no exercício do cuidado, poderá ser um caminho para reorientar os serviços e as práticas de saúde. Dessa forma, circular é conhecer, pela experiência, mais sobre o corpo, a mente, a vida sem dor e com dor, sobre si e sobre o outro; conhecimento este construído tanto pelo doente, quanto pelo terapeuta.

Inserem-se nessa ótica a criação e a multiplicação de serviços de saúde organizados a partir de equipe multiprofissional e abordagens flexíveis em direção à criação de uma ambiência que permita mudar a perspectiva do olhar sobre o círculo em direção à espiral. Um movimento que leva o olhar do corte transversal, no qual se 
pode ver um círculo bastante imperfeito, em direção ao corte longitudinal, com a possibilidade de vislumbrar uma espiral, figura que permite o deslocamento em torno de um mesmo eixo, só que em diferentes planos.

\section{Referências}

AYRES, J.R.C.M. Sujeito, intersubjetividade e práticas de saúde. Ciência e Saúde Coletiva. Rio de Janeiro, v. 6, n. 1, p. 63-72, 2001.

AYRES, J.R.C.M. Hermenêutica e humanização das práticas de saúde. Ciência e Saúde Coletiva. Rio de janeiro, v. 10, n. 3, p. 549-560, 2005.

BASZANGER, I. Pain: its experience and treatment. Soc Sci Med, v. 29, n. 3, p. 425-434, 1989.

BERKER, N. et al. Social demographic predictors of treatment outcome in chronic nonmalignant pain patients. Do patients receiving or applying for Disability Pension benefit from multidisciplinary pain treatment? Pain, v. 77, p. 279-287, 1998.

BERKER, N. et al. Treatment outcome of chronic non-malignant pain patients managed in a Danish multidisciplinary pain centre compared to general practice: a randomized controlled trial. Pain, v. 84, p. 203-211, 2000.

BOURDIEU, P. Razões práticas: sobre a teoria da ação. 3.ed. São Paulo: Papirus, 1996.

BRAIT, B. Bakhtin, dialogismo e construção do sentido. 1.ed. Campinas: Unicamp, 1997.

FERREIRA, A.B.H. Dicionário Aurélio Básico da Língua Portuguesa. Rio de Janeiro: Nova Fronteira, 1988.

KOTARBA, J.A. Chronic Pain Center. A study of voluntary client. Compliance and entrepreneurship. Amer Behav Scientist, v. 24, n. 6, p. 786-800, 1981.

LIMA, M.A.G.; TRAD, L.A.B. A dor crônica sob o olhar médico: modelo biomédico e prática clínica. Cadernos de Saúde Pública. Rio de Janeiro, v. 23, p. 2.672-2.680, 2007.

LIMA, M.A.G.; TRAD, L.A.B. Dor crônica: objeto insubordinado. História, Ciências, Saúde-Manguinhos, Rio de Janeiro, v. 15, n. 1, p. 117-133, jan.-mar. 2008.

LUZ, M.T. V Seminário do Projeto Racionalidades Médicas. Rio de Janeiro: IMS-UERJ, 1996 (Série Estudos em Saúde Coletiva, 136).

RHODES, L.A. et al. The power of the visible: the meaning of diagnostic tests in chronic back pain. Soc Sci Med., v. 48, p. 1189-1203, 1999.

SAYD, J.D. Mediar, medicar, remediar: Aspectos da terapêutica na medicina ocidental. 1.ed. Rio de Janeiro: EdUERJ, 1998. 
SCARRY, E. The body in pain. The making and unmaking of the world 1. ed. New York: Oxford University Press, 1985.

SILVA, L.A.V. Saúde e produção de sentidos práticas de mediação e translinguística bakhtiniana. Interface - Comunicação, saúde, educação, v. 7, n. 13, p. 135-148, 2003.

\section{Nota}

${ }^{1}$ As doenças crônicas têm sido consideradas o problema de saúde de maior crescimento no mundo contemporâneo, constituindo uma categoria de doença para a qual não há perspectiva de cura a partir do conhecimento médico. Esta condição tem trazido inúmeras questôes para a Biomedicina tanto em relação à duração da doença que se mantém por meses, anos ou toda a vida; envolvendo mudanças maiores ou menores para quem sofre e para os demais em seu entorno; assim como em relação ao seu gerenciamento clínico. A condição do incurável redireciona a meta terapêutica do processo sintomadiagnóstico-tratamento-cura para o gerenciamento cotidiano da doença (BASZANGER, 1989). 


\section{"Circle therapy": a metaphor for coping with chronic pains in two pain clinics}

This paper describes and analyzes the pain clinic's dynamics as a "complex product" of the biomedical therapy system, exploring the many discussions about the meaning of pain and the interdisciplinary collaboration in the therapeutic daily routines of two pain clinics, located in university hospitals in the cities Salvador and São Paulo. An ethnographic approach guided by interpretative anthropology was used to search for the description of singular and expressive situations of the pain clinic's dynamics (considered as a service, established within Biomedicine, intended for care of chronic pain). Such situations express tensions and solutions created from the confrontation of the chronic pain as a complex object that imposes flexibility to all. This ethnography focuses on four therapeutic spaces: the waiting-room, the hall, the medical consultation and the clinical case discussion. The resulting description enlightens the multiple voices on pain and interdisciplinary collaboration in the clinic's daily routines. The directions of circulation within therapeutic spaces guided this reflection around the limits and possibilities of the establishment and operation of this service.

> Key words: Chronic pain, pain clinic, interdisciplinary collaboration, heteroglossia. 